\title{
Impact of Nurse's Satisfaction on Work Performance
}

Dara Abdulla Al-Banna; Department of Nursing, College of Nursing, Hawler Medical University, Erbil, Iraq. (Correspondence: daraaq@nur.hmu.edu.krd)

\section{ABSTRACT}

Background and objective: A high satisfaction of nurses implies an improvement in effectiveness and performance in doing work or health care service. This study aimed to find out the relationship between nurse's job satisfaction and their work performance in the hospital while providing health care.

Methods: A descriptive cross-sectional study was carried out at both Hawler and Rizgary Teaching Hospitals in Erbil City of the Kurdistan Region of Iraq. A randomized-clustered sampling technique was used for enrolling 89 nurses and 27 their team-leaders through a direct interview by a questionnaire to assess nurse's job satisfaction by researcher and evaluate work performance by their team-leaders. The outcome focused on the correlation coefficient to find out the correlation between job satisfaction and work performance of nurses.

Results: The majority of the study sample was between 20 and 32 years old, Institute graduated, had fewer than five years of experience, and single among nurses with 33 and 45 years old, college graduated, more than five years, and married among team-leaders, from urban areas of both groups. Most of the nurses had fairly job satisfaction and team-leaders think that the nurses need some improvement in their work performance.

Conclusion: There was a strong positive correlation between nurse's job satisfaction and their work performance in the hospital during providing health care.

Keywords: Nurse; Team-leader; Job satisfaction; Health work performance; Correlation.

\section{INTRODUCTION}

Employees are the most important resources of all organizations. How they feel about the work and the outcomes from it have a direct impact on the organization's performance and stability. A job is a paid position of regular employment and employment is required to be financially independent and have control over life [1]. Hulin and Judge (2003) noted that job satisfaction includes multidimensional psychological responses to one's job and that such responses have cognitive (evaluative), affective (emotional), and behavioral components [2]. Job satisfaction is defined as, "the level of contentment a person feels regarding their job while work performance is the work related activities expected from an employee and how well those activities are executed by them" [3]. To measure work performance, the quality of the job has traditionally understood as being represented by the wage level, while in some sociological or industrial relations studies, it was related to working conditions. Recent developments in economics and socio-economic approaches propose additional dimensions to the definition of job quality [4]. The recent framework suggested by Green(2006) integrates these ideas and recognizes the multidimensional character of job quality through the evolution of different dimensions that including 
skills; work effort and intensification' workers' discretion; wages' risk and job insecurity' and workers' well-being and thus takes into account the multidimensional nature of job quality in work performance [5]. A nurse with a high level of job satisfaction holds positive attitudes towards his or her job in health care, while a nurse who is dissatisfied with his or her job may hold negative attitudes about the job. Therefore, job satisfaction is a key issue for health care professionals around the world and investigations reveal first of all that the organizational features of a structure usually a hospital can greatly influence the job satisfaction of nurses [6].

However, the total organizational performance depends on the efficient and effective performance of individual employees of the organization. Therefore, every organization places a considerable reliance on their individual employee performance to gain high productivity in the organization [7]. A large empirical literature exists that explores the determinants of organizational performance including the determinants of financial performance and the determinants of labor productivity. Many studies are based on firm-level data. One might argue, however, that, in order to understand the determinants of firm performance, it is important to analyze employee level of job satisfaction given that the behavior of employees and the decisions they make may influence workplace performance [8]. From the above definitions, it is clear that nurse's job satisfaction is an unobservable variable. Job satisfaction can be affected by the work performance of nursing care and can directly impact the productivity of each organization or hospital. In examining in outcomes of job satisfaction, it is important to breakdown the analysis into a series of specific set of variables regarding nurse's satisfaction and evaluating form of work performance. The main objective of this study was to find out the correlation between nurse's job satisfaction and their work performance, evaluated by their team-leaders.

\section{METHODS}

A cross-sectional study design was conducted among nurses and their teamleaders to find out the relationship between job satisfaction and their work performance, from April to July 2017 at two hospitals of Rizgary and Hawler Teaching Hospitals in Erbil City in the Kurdistan Region of Iraq. One hundred sixteen nurses enrolled in this study. They were divided in to two groups: the first group consisted of 89 nurses in different wards and units; the second group included 27 team-leaders of the nurses. The participants are working in the two hospitals of Rizgary and Hawler Teaching Hospitals in Erbil City in the Kurdistan Region of Iraq. Non-randomizedclustered sampling technique was used to establish a representative sample of the target population, according to the study's inclusion and exclusion criteria. Both men and women were included. Agreed to be subject in this study with good personal communication. Administrative nurses (nurses working in offices without direct contact with patients) and who was in vacation and night shift was excluded. Nurses group were asked about their job satisfaction, while team-leaders group were asked to evaluate these nurses who participated in the study. The sample size estimated based on the following parameters through the G-Power software Version 3.1 in two tails: Alpha I error/ level of significance $=0.05$ in $95 \%$ confidence interval Power (1-Beta II error) $=80 \%=0.8$, Effect size (0.257) of correlation (0.0663) of the previous study. The data were collected through a direct interview by the researcher in the Kurdish language after translating from English versions and vice versus. 
The data collection tool was prepared by the researcher based on literature review, prior studies, and expert recommendations from the field. The questionnaire consisted of two different forms. The first questionnaire designed for nurses included 17 sociodemographic characteristics of the nurse and questions regarding job satisfaction, which that contained 17 questions distributed on five main domains "general working conditions, pay and promotion potential, work relationships, use of skills and abilities, and work activities". Job satisfaction questions allowed for three levels of satisfaction (unsatisfied, moderately satisfied, and satisfied), scored from one to three. The second questionnaire for teamleaders who leading above described nurses that included 14 questions related to sociodemographic characteristics of the team-leaders and 14 questions regarding evaluation of nurse's work performance of health care by their team-leader with responds of five level of work performance (major improvement needed, some improvement needed, meets expectations, often exceeds expectations, and consistently exceeds expectations) scored from one to five. The validity of the questionnaire was checked initially by experts from different related of nursing and administrative specialties. The expert responses were based on agreement or disagreement with items of questionnaire. The results indicated that all experts agreed the content of the questionnaire with some modifications. The researcher took into consideration their responses and prepared the final version of the questionnaire. A pilot study was carried out in two wards of each hospital (11 nurses and 2 team-leaders) to determine the reliability of the questionnaire (internal consistency by split-half). The alpha correlation coefficient was 0.842 , which is statistically adequate. The formal permission obtained from both of the
Ethical and Scientific Committees in the College of Nursing/ Hawler Medical University. Informal oral consent was obtained from each participant, and all patients' information was kept confidential. In addition, the researcher told each participant that their participation was voluntary work, and that they were free to leave at any time, even the interview process was not finished. After data collection, the variables and data were entered to statistical application (Statistical Package for Social Science -SPSS Version 23). The data were analyzed through using SPSS software that included descriptive statistical analysis (Frequency, Percentage, Mean, and Standard Deviation) and inferential statistical analysis (Spearman Correlation Coefficient). The confidence interval was $95 \%$. The P-value of each test $\leq 0.05$ considered as statistically significant, power 0.80 , and correlation between \pm 1 .

\section{RESULTS}

Table 1 shows the sociodemographic characteristics of the 89 nurses and 27 their team-leaders. Regarding age group, the highest percentage of the study sample was between ages 20-32 years old among nurses (76.5\%) while it was between ages 33-45 years old among teamleaders (70.4\%). More than half of the study sample were female among nurses; but most of the team-leaders were male (92.6\%). Concerning the level of education, among the nurses the majority had graduated from a medical institute (75.3\%), while half of the team-leaders had graduated from a medical institute and others from nursing college. Half of the nurses had fewer than five years of experience, but among team-leaders, the majority had more than five years of experience (89\%). Half of the nurses were unmarried, while most of team-leaders were married (85.2\%). 
Finally, most of the study participants were from urban areas including $86.5 \%$ of nurses and $100 \%$ of team-leaders.

Table 1: Sociodemographic characteristics of nurses and team-leaders

\begin{tabular}{ccc}
\hline $\begin{array}{c}\text { Sociodemographic } \\
\text { Characteristics }\end{array}$ & $\begin{array}{c}\text { Nurse } \\
(\mathbf{n = 8 9 )}\end{array}$ & $\begin{array}{c}\text { Team- } \\
\text { leader } \\
\text { (n=27) }\end{array}$ \\
\cline { 2 - 3 } & $\mathbf{F ~ ( \% )}$ & $\mathbf{F ~ ( \% )}$ \\
\hline Age group (years) & & \\
$20-32$ & $68(76.5)$ & $4(14.8)$ \\
$33-45$ & $19(21.3)$ & $19(70.4)$ \\
$46-58$ & $2(2.2)$ & $4(14.8)$ \\
Gender & & \\
Male & $43(48.3)$ & $25(92.6)$ \\
Female & $46(51.7)$ & $2(7.4)$ \\
Education level & & \\
Institute graduated & $67(75.3)$ & $13(48.1)$ \\
College graduated & $22(24.7)$ & $14(51.9)$ \\
Years of experience & & \\
<5 & $49(55.1)$ & $3(11.1)$ \\
6-10 & $26(29.2)$ & $11(40.7)$ \\
11-15 & $8(9)$ & $10(37.1)$ \\
$>15$ & $6(6.7)$ & $3(11.1)$ \\
Marital status & & \\
Single & $48(53.9)$ & $4(14.8)$ \\
Married & $39(43.9)$ & $23(85.2)$ \\
Divorced & $2(2.2)$ & $0(0)$ \\
Residency area & & \\
Urban & $77(86.5)$ & $27(100)$ \\
Rural & $12(13.5)$ & $0(0)$ \\
Total & $\mathbf{8 9 ( 1 0 0 )}$ & $\mathbf{2 7}(\mathbf{1 0 0})$ \\
\hline
\end{tabular}

Table 2 shows nurses' job satisfaction about their work. The majority of nurses responded saying they were fairly satisfied regarding general working conditions and work relationships $(46.1 \%$ and $43.8 \%$ respectively). However, the majority of the participants responded saying they were dissatisfied regarding pay and promotion potential, use of skills and abilities, and work activities (52.8\%, 48.3\%, and $46.1 \%$ respectively). The overall level of nurse's satisfaction was fairly satisfied which present $69.7 \%$, but $21.3 \%$ and $9 \%$ for each of dissatisfied and satisfied respectively. Regarding overall evaluation of nurse's work performance by their team-leaders, results in Table 3 show that most the majority of the team-leaders indicated that the nurses required some improvements $(85.2 \%)$, while $14.8 \%$ of the team-leaders suggested the nurses required major improvements Unfortunately, there no nurses met the expectations of their work performance of providing care.

Table 4 describes the correlation between the job satisfactions of nurses with their evaluation of work performance by their team-leaders which there is a nearly matching mean scores between the above two variables $(\mathrm{M} \pm \mathrm{SD}=1.88 \pm 0.540$ and $2.04 \pm 0.366$ respectively). There is a very highly statistical significant correlation between nurse's job satisfaction and their work performance ( $p$-value $=<0.001)$. The correlation between the two described variables is strong $(r=0.712)$ with positive direction of the correlation.

Table 2: Level of Job satisfaction among nurses

\begin{tabular}{lccc}
\hline \multicolumn{1}{c}{ Questions regarding nurse's job } & Dissatisfied & Moderately satisfied & Satisfied \\
\cline { 2 - 4 } \multicolumn{1}{c}{ satisfaction } & F (\%) & F (\%) & F (\%) \\
\hline General working conditions & $15(16.9)$ & $41(46.1)$ & $33(37.1)$ \\
Pay and promotion potential & $47(52.8)$ & $39(43.8)$ & $3(3.4)$ \\
Work relationships & $13(14.6)$ & $39(43.8)$ & $37(41.6)$ \\
Use of skills and abilities & $43(48.3)$ & $30(33.7)$ & $16(18)$ \\
Work activities & $41(46.1)$ & $39(43.8)$ & $9(10.1)$ \\
Overall Nurse Satisfaction & $\mathbf{1 9 ( 2 1 . 3 )}$ & $\mathbf{6 2 ( 6 9 . 7 )}$ & $\mathbf{8}(\mathbf{9 )}$ \\
\hline
\end{tabular}


Table 3: Overall evaluation of nurse's work performance by their team-leaders

\begin{tabular}{lcc}
\hline \multicolumn{1}{c}{$\begin{array}{c}\text { Overall evaluation of nurse's work perfor- } \\
\text { mance by their team-leaders }\end{array}$} & F & (\%) \\
\hline Major improvement needed & 4 & $(14.8)$ \\
Some improvement needed & 23 & $(85.2)$ \\
Meets expectations & 0 & $(0)$ \\
Often exceeds expectations & 0 & $(0)$ \\
Consistently exceeds expectations & 0 & $(0)$ \\
$\quad$ Total & $\mathbf{2 7}$ & $\mathbf{( 1 0 0 )}$ \\
\hline
\end{tabular}

Table 4: Association between nurse's job satisfaction and their work performance

\begin{tabular}{llllcl}
\hline $\begin{array}{c}\text { Association between nurse's } \\
\text { job satisfaction and their work } \\
\text { performance }\end{array}$ & Mean & $\begin{array}{c}\text { Standard } \\
\text { Deviation }\end{array}$ & P-value & $\begin{array}{c}\text { Correlation } \\
\text { Coefficient } \\
\text { Strength }\end{array}$ & Direction \\
\hline Nurse's job satisfaction & 1.88 & 0.540 & $<0.001$ & 0.712 & Positive \\
Nurse's work performance & 2.04 & 0.366 & VHS & Strong & \\
\hline
\end{tabular}

\section{DISCUSSION}

The aim of the current study was to find out the relationship between nurse's job satisfaction and their work performance which was evaluated by their team leaders. Regarding the sociodemographic characteristics of both nurses and team-leaders, the highest percentage of the study sample was between ages 20 to 32 years old among nurses, while it was between ages 33 to 45 years old among team-leaders. Because all of the nurses graduated from medical institute and college of nursing and these institutions are newer than preparatory of nursing, the majority of the nurses are in the twenties of age. More than half of the study sample was female among nurses; but most of the teamleaders were male. Traditionally most of leaders are male. Concerning the level of education, among the nurses, most had graduated from a medical institute, while half of the team-leaders were graduates from the medical institute and others from the college of nursing. Half of the nurses are single, while most of team-leaders were married. These results supported by a study done in Kingdom Saudi Arabia by Almaliki et al in 2012 they found that the highest percentage of their study sample of nurses were aged between 20 and 29 years old, female, had a diploma, and were not married $[9,10]$. Half the nurses had fewer than five years of experience, but most team-leaders had more than five years' experience. This result is supported by the study which was done in Public Hospitals-Libya by Ali et al in 2014, which showed that nearly half of the staff has fewer than five years with regards to working experience in hospitals [2]. Concerning the level of job satisfaction among nurses, the highest percentage of the nurses answered fairly satisfied regarding general working conditions and work relationships, while the highest percentage of the participants answered that they were dissatisfied 
regarding pay and promotion potential, use of skills and abilities, and work activities. The overall level of nurses' satisfaction was fairly satisfied and others were dissatisfied with less satisfied nurses. The political instability, financial crises, lack of salary and payment, wars, food insecurity, unclarity of future and missing of basic human needs affected employees' satisfaction particularly among nurses. The present findings agreed with other studied done in different areas and countries as following: In a study done in Libya in 2014 under the title of "Job Satisfaction, Organizational Behavior, and Training to Improve Employees Performance" about the relationship between hospital staff and human resource managers, the relationship between hospital staff and managers is sometimes breakable. The nurses and staff may feel uncomfortable giving unfavorable opinions about managers because of worries about job security, while managers and supervisors wonders if nurses and staff are working to the best of their ability. The absence of incentives and low salaries were two main reasons for reported poor job satisfaction, and according to the job satisfaction factor in medical sector had a negative effect on staff's performance. They also measured the incentives that employees received during their past period working in public hospitals. Because incentives and salary are of the main factors that increase and improve performance at any organization. The result showed that 38 out of 56 respondents were disagreed and strongly disagreed. The incentive systems to medical and staff in Libyan public hospitals was approximately the major percentage of hospital staff revealed no incentives and less salary have been given to them in the past, which shows the lack of real incentives and salary giving to hospital staff in order to give them higher motivation and push them to work better and give their best output to their organization. The findings of the present study regarding the nurses job satisfaction supported findings from other studies conducted in Bangalore, Iran, and Turkey by Ramesh et al, Saraji and Dargahi, and Sirin in 2013, 2006, and 2015. The findings revealed that respondents were dissatisfied with their work life and these findings are consistent with findings of a number of previous studies where nurses were not satisfied with their work life $[2,11$ $-13]$.

Regarding the overall evaluation of nurse work performance by their team-leaders, most of the team-leaders suggested that nurses required some improvement, while fewer team-leaders suggested that the nurses required of needing the major improvement by nurses. Unfortunately, there are no nurses meet the expectations in their work performance of providing health care. This is because of that most of the nurses were fairly or not satisfied with their job. The study results agreed with the study done by Becton and Matthews in the USA during the years 2011 to 2012, they found that the nursing quality has a significant impact on patient outcomes. Research has shown that the job performance of nurses is the single largest predictor of patients' satisfaction and significantly affects patients' health outcomes during and after hospitalization. Therefore, the consequences of poor nurse performance are significant to improve the job performance of nurses [14]. The present study found that there is an association between nurse's job satisfaction and their work performance which was evaluated by their team-leader. There was a very high statistically significant correlation between nurse's job satisfaction and their work performance. The correlation between the two described variables is strong with the positive direction of the correlation. This association is important for health care 
and hospital outcomes. This expected result supported by many studies. Authors Platis et al presented a study under the title "Relation between job satisfaction and job performance in healthcare services", they showed that self-satisfaction of quantity of work versus self-satisfaction of productivity has a significant, strong, and positive correlation $(r=0.76)$. In this work investigation of the performance for the quality of job satisfaction and self-job satisfaction for nurses is taking place. For the job satisfaction, two factors have been introduced which are manager administration and job productivity, explaining the $68.7 \%$ of the total information. Furthermore, the ability of nursing managers to communicate with the employees and respect their opinions in considered of high importance for the nursing staff satisfaction [9]. In a study which was done in Pakistan by Khan et al, in 2011 entitled "Impact of job satisfaction on employee performance: An empirical study of autonomous Medical Institutions of Pakistan" they found that the relationship between productivity (often under the form of personal achievements) and satisfaction in job is also considered strong [15]. In a study about employee motivation and organizational performance, employee attitude and job performance are essential to the success of the organization, regardless big or small. In the modern workplace, human resources are valued above all other values, so motivated, happy personal feelings, opinions, attitudes of nurses and committed employees are the productive employees and play a critical role in their performance [16]. Creating and maintaining a healthy work life for nurses is very important to improve their work satisfaction, which lead to improves nursing care outcomes [10]. The present study concluded that there was a strong positive association between nurse job satisfaction and their work performance in hospital in providing health care. The implications of this study are helpful for planning and increasing the level of nurse job satisfaction. This could be done through improving working hours, flexibility in scheduling, area of work, and offering adequate amount of paid vacation time or sick leave; in security and potential promotion like pay of salary in its time and amount, assurance, and job security; also in elevating work relationships for increasing relationships with coworkers, team-leaders, supervisors, and head of departments; improving skills and abilities through participating nurses in training courses, opportunity to learn new skills then utilizing their skills and talents. Furthermore, it is important to increase work activities including improving the variety of job responsibilities, increasing the degree of independence, delegating authorities, and adequate opportunity for periodic changes in duties.

\section{Study limitations}

Although the present study described important findings, no study is without limitations, First, this study was conducted within two large hospitals within the same Erbil City. While the study focused on the prediction of the job performance of nurses, it is possible that the present study findings may be a performance and outcome of some locally or regionally specific factors which could not be controlled. Second, this study focused on nurses who are working in these two big hospitals. It should be noted that nurses are working in other types of healthcare organizations in addition to hospitals, such as nursing homes, health clinics, medical practices, and other outside places of the hospital. As a result, the study design may limit the generalizability of the results to other settings. Future studies could include nurses from a variety of healthcare organizations in a variety of locations. 


\section{ACKNOWLEDGEMENT}

My warmest thanks and wish of health go to the sample who participated in this study. I express my much appreciation to everyone who helped directly or indirectly with the accomplishment of this study particularly during data collection.

\section{CONFLICTS OF INTEREST}

The author reported no conflict of interests.

\section{REFERENCES}

[1] Munisamy S. Identifying factors that influence job performance amongst employees in oil palm plantation-FASS Final Project (Psychology). 2013.

[2] Ali AE, Kertahadi MC, Nayati H. Job Satisfaction, Organizational Behavior, and Training to Improve Employees Performance Acase: Public Hospitals-Libya. Journal of Business and Management. 2014;16(8):7582.

[3] Wright BE, Davis BS. Job satisfaction in the public sector: The role of the work environment. The American Review of Public Administration. 2003 Mar;33(1):7090.

[4] Gallie D, editor. Employment regimes and the quality of work. Oxford University Press; 2009.

[5] Davoine L, Erhel C, Guergoat-Larivière M. A taxonomy of European labour markets using quality indicators. 2008.

[6] Bhatnagar K, Srivastava K. Job satisfaction in healthcare organizations. Industrial psychiatry journal. 2012 Jan;21(1):75.

[7] Pushpakumari MD. The impact of job satisfaction on job performance: An empirical analysis. In City Forum 2008 Jan 1 (Vol. 9, No. 1, pp. 89-105).

[8] Brown S, McHardy J, McNabb R, Taylor K. Workplace performance, worker commitment, and loyalty. Journal of Economics \& Management Strategy. 2011 Sep 1;20(3):925-55.

[9] Platis C, Reklitis P, Zimeras S. Relation between job satisfaction and job performance in healthcare services. Procedia-Social and Behavioral Sciences. 2015 Feb 12;175:480-7.

[10] Almalki MJ, FitzGerald G, Clark M. The relationship between quality of work life and turnover intention of primary health care nurses in Saudi Arabia. BMC health services research. 2012 Sep 12;12(1):314.

[11] Sirin M, Sokmen SM. Quality of Nursing Work Life Scale: The Psychometric Evaluation of the Turkish Version. International Journal of Caring Sciences. 2015 Sep 1;8(3):543.

[12] Ramesh N, Nisha C, Josephine AM, Thomas S, Joseph B. A study on quality of work life among nurses in a medical college hospital in bangalore. National Journal of Community Medicine.2013;4(3): 471-74
[14] Becton JB, Matthews MC, Hartley DL, Whitaker LD. Using biodata as a predictor of errors, tardiness, policy violations, overall job performance, and turnover among nurses. Journal of Management \& Organization. 2012 Sep;18(5):714-27.

[15] Khan AH, Ahmad I, Aleem M, Hamed W. Impact of job satisfaction on employee performance: An empirical study of autonomous medical institutions of Pakistan. International Journal of Management and Innovation. 2011 Jul 1;3(2):1.

[16] Dobre Ol. Employee motivation and organizational performance. Review of Applied Socio-Economic Research. 2013;5(1):53-60. 